\title{
An Information Literacy Course for Doctoral Students: Information Resources and Tools for Research
}

\author{
Best Practice Article
}

Kristiina Hintikka and Ann-Louise Paasio*

University of Turku

\begin{abstract}
The purpose of this paper is to showcase the information literacy course for doctoral students called Information Resources and Tools for Research. Turku University Library organises this course in collaboration with the University of Turku Graduate School. The course, which was started in 2012, has been organised four times so far, twice in English and twice in Finnish. The course offers training to all doctoral Programs in all of the seven disciplines present at the University of Turku and doctoral candidates of the University. In our presentation we will describe the structure and contents of the course and share our experiences of the collaboration with the University of Turku Graduate School. In addition, we will describe how the information specialists of the Turku University Library have collaborated during the course. We will also discuss the challenges of the course. Based on the course feedback, it can be stated that in general, participants have found this course very useful for their research in the University of Turku.
\end{abstract}

\section{Keywords:}

Information literacy, doctoral students, phd students

\section{*Contact:}

Ann-Louise Paasio, University of Turku , Finland e-mail: alpaasio@utu.fi

Nordic Journal of Information Literacy in Higher Education, 2015. (C2015 Kristiina Hintikka \& Ann-Louise Paasio 


\section{Introduction}

The University of Turku is one of the largest multidisciplinary universities in Finland with approximately 20000 students. The university has seven faculties: Faculty of Humanities, Faculty of Mathematics and Natural Sciences, Faculty of Medicine, Faculty of Law, Faculty of Social Sciences, Faculty of Education and Turku School of Economics. Annually, there are around 2000 postgraduate students at the University of Turku. The University of Turku Graduate School (UTUGS) was established in August 2011. The Graduate School consists of local and national doctoral programs which cover all disciplines and doctoral Candidates of the University. The Graduate School provides systematic and doctoral training on academic topics as well as on generic skills and career planning.

Before 2012 the Turku University Library offered information literacy teaching throughout the university curriculum, but for various reasons it did not reach doctoral students. There was a strong need to include also doctoral students and researchers in the curriculum for information literacy. When the University of Turku Graduate School (UTUGS) was established, the library contacted the coordinator of UTUGS and agreed that the library would be responsible for the IL training and that the first information literacy course for doctoral students would take place in spring 2012. The course blended well into the other generic skills courses of UTUGS (http://www.utu.fi/en/research/utugs/Pages/home.aspx).

Information Resources and Tools for Research course is designed for doctoral candidates who want to learn to use both the printed and the electronic resources more effectively, manage their references and have the basic knowledge of scientific publishing. The course has consisted of computer class sessions, lectures and assignments. The course material and assignments have been delivered and administered in the Moodle virtual learning environment. The participants have received 1 ECTS (European Credit Transfer System) for completing the elective course, and the credit administration has been handled by UTUGS.

According to the Association of College and Research Libraries (ACRL), information literacy is a set of abilities enabling individuals to "recognize when information is needed, and be able to locate, evaluate, and use effectively the needed information." The information literacy training at the Turku University Library is based on the ACRL Information Literacy Competency Standards for Higher Education.

\section{Literature overview}

Doctoral students are often at the early stages of their research career. During their dissertation work they need to find, manage and view large bodies of secondary, published research resources (JISC \& British Library, 2012, 68). PhD students have access to a wider range of research resources than ever before. This has led some researchers, especially beginning researchers, to complain about 'information overload'. (Merimaa, 2012, p. 8.) In recent years there has been increasing recognition in the academic circles of the importance of information training for postgraduate students. For example, the Academy of Finland included information and data management skills in the list of examples of transferable skills to be integrated to the doctoral training (Academy of Finland, 2011).

There is not much literature on generic, multiple session IL courses for PhD students. Secker and Macrae-Gibson (2011) describe a generic six-week information literacy course for $\mathrm{PhD}$ students at London School of Economics and Political Science. Heading, Siminson, Purcell, and Pears (2010) report on information literacy and management skills training for postgraduate researchers that consisted of two three-hour workshops. In a recent article Madden (2014) describes information behaviour of Humanities PhDs on an IL course, which comprises 15 hours of class-contact time and online material. Seiler (2009) and Seiler, Miil, and 
Lepik, (2012) give an overview of online courses that they have offered for doctoral students and undergraduates at the University of Tartu.

Survey conducted by the Finnish National Electronic Library (Merimaa, 2012) analysed the use of electronic resources of over 3800 researchers from all disciplines and sectors, including also postgraduates (30\% of respondents). More than $20 \%$ of the respondents expressed interest in training opportunities on using portals and databases, as they were having problems e.g. with refining keyword searches, but also indicated that they do not have time to attend training. The respondents indicated that their limited skills both in information retrieval and in evaluating the relevance of the materials tended to hide valuable resources in the middle of the numerous search results. According to the study, the most popular starting point for the search of academic material was Google Scholar, but also library portals were often used by the respondents. It may be that the need for user education is higher than the report shows, because researchers tend to overestimate their information skills. (Merimaa, 2012, pp. 38, 73.)

According to several studies, PhD students value individual, one-to-one interaction and guidance that is more advanced and tailored to their own subject area or to their needs. (JISC \& British Library, 2012; Madden, 2014, p. 12; Secker \& Macrae-Gibson, 2011, p. 104). Skill-based workshops are preferred over theoretical content. Collaboration between the faculties and programmes of the university is emphasized in many studies and the embedding of the IL course into the curricula has been considered important for the success of the course. (Hoffmann, Antwi-Nsiah, Feng, \& Stanley, 2008; Secker, 2012, p. 105; Secker \& Macrae-Gibson, 2011, p. 123).

\section{Grouping the participants}

Since the beginning of the course in 2012, there have been different composition variations of the subject-specific groups, depending on the subject fields of the enrolled students. The group of science, technology, and medicine graduates has always remained the same however and it has been also the largest group.

In the first Finnish course in spring 2012 there were four groups: 1 . science, technology and medicine, 2 . business, economics and law, 3. education, social sciences and humanities (history, culture and arts), 4. linguistics. Since for some reason, the interest has been so low among humanists, it has been necessary to re-organize the groups. In spring 2013 there were two courses - one in English, one in Finnish - and there, the humanities, social sciences, business, economics, education and law formed one group in the English course and the humanities and education formed one group in the Finnish course.

In spring 2014, the Information Resources and Tools for Research consisted of 15 hours of compulsory computer class sessions and lectures during a six-week period. The sessions took place once a week and lasted for three hours. The course participants worked in the following groups according to their subject speciality: 1 . science, technology and medicine 2 . humanities and social sciences 3 . business, economics, education and law.

\section{Course outline}

Since the beginning, the outline of the course has remained mainly the same, but some changes have been made to the course content based on the received feedback. Next, the course outline for spring 2014 will be presented in more detail.

\section{Brush up session}

During previous courses, tutors had become aware that the participants had various levels of skills when starting the course. The aim of the brush up session, which was introduced in spring 2014, was to ensure that the students mastered the basic library skills needed to manage the assignments of the course. In addition, the voluntary session made it possible to show the 
participants that the basic skills training would not be included in the actual course. The brush up session was not compulsory for all, but instead students could attend it, if they felt they needed brush up in library skills such as using library databases to find books and journals.

\section{Session 1: Building your search}

The first session was about subject database searching and search building. Before this session, the participants had already submitted their first assignment in the virtual learning environment Moodle. In this assignment, they were asked to conceptualise their research topic and make a list of the possible search terms related to their topic. Furthermore, they had to explore the ResearchGuides in their own field. Then when coming to the class they could start practicing database searches with their search words and use the classroom time effectively. In addition, the assignments helped the information specialists, as tutors, to familiarize with the students' research topics and search terms beforehand.

During the session, the participants worked in the three groups of disciplines described above. The aim of this session was to introduce relevant subject databases and thesauri and maybe most importantly, to give students a possibility to work with their own research topics by providing plenty of time for hands-on training with the tutors' support. During the class, the tutors gave short database introductions, which were followed by hands-on time. Students acquainted themselves with new subject databases and performed searches using the search terms they had thought of for the first assignment.

After this session followed the second assignment - Building your search. Students were required to create a search string that they could use for searching on their own topic and test the search string in a database. Secondly, they had to explore a new database that they had not used before. The students had five days to post the assignment in Moodle after which the tutors commented on them.

\section{Session 2: Reference Management (RefWorks)}

In the second session, the participants were introduced to the RefWorks reference management program offered by the Turku University Library. The aim was to train participants in using a bibliographic software management tool, which would help them to organize and manage the electronic references retrieved using, for example, the databases presented during the previous session. In addition, they acquainted themselves with RefWorks's Write-n-Cite tool, which allowed them to add and format citations and bibliographies while writing their paper. The students were shown the Reference Management ResearchGuide created by the Turku University Library, which also contains short descriptions of alternative softwares, such as Zotero or Mendeley.

The third assignment following upon this session was to create a short document with some text and a bibliography using RefWorks. This time the students were allowed to do the assignment at the end of the class and submit it in Moodle immediately.

\section{Session 3: Refining your search}

The third session was again about database searching. The tutors introduced a couple of new databases and students got time for hands-on training. This session was also a new addition, in the previous courses there had been only one database session but now it was decided to try one more to see how it worked out. In this way, students got more time for hands-on training with the tutors' support and they could also continue to practise the downloading of the results of their searches into RefWorks.

After the session students received the last assignment, where they were asked to modify their search string from two weeks ago for at least two of the most important databases relevant to their subject and include a short evaluation of their searches. 


\section{Session 4: Lecture/Seminar}

The fourth session, which was a half-day seminar, included lectures on scientific publishing, bibliometrics, ethics of scientific publishing, plagiarism and on the Research information system. This seminar was meant for all participants, but was also open for others in the university interested in these topics. Some of the lectures were given by the information specialists, and for some lectures speakers from the university were invited.

\section{Session 5: Keeping up}

The last session included training on how to keep up with current research. Students were introduced to some effective methods of keeping up to date such as setting up alerts, RSS feeds, RefAware and Mendeley. Furthermore, we talked about how to find citations and Impact Factors, and there was also training on the Finnish Publication Forum (http://www.tsv.fi/julkaisufoorumi/english.php?lang=en).

\section{Session 6: Extra session}

An extra session was also organized for those interested in getting further help on their subjects. In addition, students were able to attend this session, if they had missed some of the previous compulsory sessions, and thus compensate for their earlier absence.

\section{The virtual learning environment Moodle}

The first course in spring 2012 was announced on our library's website and all the course material was also made available through that site. Since 2013, the web learning environment Moodle has been used for delivering and administering the course material and assignments. The students have been able to access all their study material via Moodle and no handouts have been provided during classes. As the main study material we have used the University of Oulu Toolbox of Research, which is a comprehensive online information package commonly used in Finnish university libraries. The link to this material as well as links to our field-specific ResearchGuides has been provided in Moodle. Other materials in Moodle have consisted of database tutorials both as pdfs and videos. The Moodle course area has remained available for the students also after the end of the course.

\section{Collaboration}

Information Resources and Tools for Research course was started in 2012 and the course contents were planned in cooperation with the UTUGS coordinator. The library's chief information specialist and the coordinator together decided the main topics of the course. To address the complexity of the postgraduate level information training, the course was planned to include multiple sessions. When designing the course, one of the main elements was that other experts at the university would be invited to lecture on topics such as ethics and plagiarism. Later on the information specialists have developed the course according to the students' feedback.

The course has been advertised on the web pages of UTUGS and of the library and in the university's intranet. The credit administration has been handled by the UTUGS coordinator. After the course, she has been sent a list of the participants, who have passed the course and she has recorded the credits in the study register. At the beginning, the feedback questionnaire was planned and sent to the participants by the UTUGS coordinator, and she also forwarded the results to the tutors. Spring 2014, the feedback questionnaire was managed altogether by the library. UTUGS has been responsible for the budget, for example they have paid for the invited lecturers.

In spring 2014, all the library's seven information specialists collaborated in the planning of the course structure and course material and participated as course tutors. There were 2-3 tutors per subject-based group and they remained with the same group for the whole course. 
During hands-on sessions, tutors took turns in giving short database introductions and after that both of them circled in the classroom providing assistance if needed. Both students and tutors benefited from this. Tutors could provide plenty of time for each student and give more detailed help if someone needed that. In addition, tutors got an opportunity to learn from each other. Overall the atmosphere in the class was informal.

After the course, the course feedback has been analysed together and the course has been developed based on the feedback.

\section{Course feedback from students}

After the course, all students have been asked to complete a feedback form on the course. In spring 2014, 29 students completed the course and 20 of them answered the feedback questionnaire. The feedback from 2014 showed that the course was rated either good or excellent.

\begin{tabular}{|l|c|c|c|c|c|c|c|}
\hline$(1$ is poor, 5 is excellent $)$ & $\mathbf{1}$ & $\mathbf{2}$ & $\mathbf{3}$ & $\mathbf{4}$ & $\mathbf{5}$ & $\mathbf{\%}$ & Average \\
\hline Overall course grade $\%$ & 0 & 0 & 0 & 60 & 40 & 100 & 4,4 \\
\hline
\end{tabular}

On the form, students have also been able to describe their experiences of the course in their own words. In general, the course feedback from 2012-2014 has been positive. One student commented:

"Thank you, this was a great course and I would recommend it for anyone who is involved in academic writing! " (2014)

\section{Assignments and databases}

The following two comments show that these students have benefited from the assignments:

"Course was really well prepared! And the assignments were helpful" (2014)

"Own assignments promoted learning during the whole course." (2013)

During the database instruction sessions students have been encouraged to search for materials on their own topics in the subject specific databases. Here are some reflections on these sessions:

"Now I understand much better how to use databases and research tools."(2013)

"I am sure that without this course I would not be able to find any information, especially in law." (2013)

\section{Individual guidance}

Students have seemed to be satisfied with the individual guidance. As two respondents stated:

"The lecturers were extremely helpful and patient to guide me personally." (2013)

"I felt the lecturers were enthusiastic, well prepared and could give also attention to personal questions." (2013)

\section{Experience sharing}

Attending the course has offered doctoral students an opportunity to interact with each other. One student wrote about this:

"I think it is useful to have these kinds of courses and forums where PhD researchers from different faculties can share their skills and develop methods in conducting their research, such as data collection, using archives and online materials." (2014)

\section{RefWorks}

The reference management software RefWorks has been especially popular, and it has been mentioned in several comments:

"My goal was to learn to use RefWorks and I did." (2014) 
"I have been using the resource several times a week ever since the lecture introducing it." (2014)

\section{Own motivation}

Some students have talked about their motivation to attend the course:

"I have already for a long time wanted to learn better the topics covered in this course, so I was rather motivated to participate" (2014)

"I was very motivated to learn skills in practice and my previous skills were very poor before the course." (2014)

\section{Challenges}

\section{Challenges for tutors}

One of the challenges of the information literacy instruction for doctoral students is the heterogeneity of the groups. Individual students differ in terms of subject areas as well as their backgrounds, skills and life situations. Some have continued with their doctoral studies directly after graduating and may have up-to-date skills in, for example, using databases. Others might have years since their graduation or they are international students new to the university and almost everything might be new to them.

On the course, students have been divided into groups, where the subject areas are as close to one another as possible. However, even within the same field, the interests and research topics of the participants can vary greatly. During the three-hour hands-on classes, however, there has been plenty of time for personal guidance, and tutors have been able to focus on the specific needs of the students.

In addition, going through the assignments and giving feedback to students has been time consuming, and it has been necessary to reserve enough time for this. There has also been often a need to remind students about upcoming deadlines and to ask for additions and modifications. Due to the high staff commitment need the course has been organized during spring when there have been fewer undergraduate library training sessions.

\section{Challenges for students}

One of the challenges for students, according to the course tutors, has seemed to be the finding of relevant search terms and designing search strings although their research topic has been clear. In addition, some students have seemed to be uncertain whether they have searched all the important databases.

Another challenge has been the time-constraints that many doctoral students face, as they often study part-time (Academy of Finland 2011, 8). The following participants have reflected on this:

"Recorded lectures would help in case when there are difficulties to participate in the training" (2013)

"In my view, this kind of working could be also conducted online, with lync or similar telecommunication methods (this would be also an additional resource for research that could be practiced simultaneously)" (2014).

\section{Dropouts}

On the whole, doctoral candidates have seemed to be motivated to attend the training and they have considered information literacy skills important. There have been some dropouts each year, but their number has decreased. In spring 2014, $74 \%$ of the registered students passed the course. However, in order to find out more about the reasons for dropping out, a dropout questionnaire was sent to all students, who had discontinued the course in spring 2014. 
Unfortunately, only a few answered. As expected, scheduling problems were mentioned, and suggestions for improving the course included online delivery:

"It would be great that courses would be arranged so that they would be grouped with another course for the same day or be arranged with online or e-learning."

"This time it did not fit in my schedule as I had planned, there were too many overlappings with other courses."

\section{Conclusions and future plans}

In this best practice paper, we have described the Information Resources and Tools for Research course for doctoral students at the University of Turku. The elective and credit-bearing course was created in collaboration with the University of Turku Graduate School and it has now established itself as part of the UTUGS program. Working with the UTUGS program to tailor the course content to the needs of the PhD students and to market the course has been crucial in order to reach the intended audience. The course has received positive feedback from the participants.

During the six-week period, students have worked with the different aspects of information training, concentrating on their own research topic. Practical training on e.g. information seeking and RefWorks has been combined with lectures on scientific publishing, open access, research information system and ethics. '

As Secker and Macrae-Gibson (2011, p. 106) have stated, one of the advantages of the multiple session course is that it allows skills development. The aim of the UTUGS course has been to allow students to construct learning experiences by letting them practise and build upon prior knowledge. The subject-based groups have worked with the same tutors throughout the entire course. This has allowed students and tutors to develop a relationship and has given tutors a chance to follow students' skills development. Furthermore, the course has been team taught since the beginning, allowing tutors to also learn from each other.

Postgraduates form a very diverse group. At this level it is especially important to take into consideration the differences between subject areas, and between the competencies and backgrounds of the students. In this generic, transferable skills course, the course structure has been the same for all disciplines, but the hands-on training (excluding RefWorks session) has taken place in smaller subject specific groups. In their feedback, students have given positive comments, for example, on the assignments and class activities which have focused on their own research topics. The participants have also valued the personalized support from the subject information specialists.

One of the challenges of the current course has been that the students are asked to be present at five sessions. This can easily cause scheduling problems for doctoral students, as the course feedback also showed. In the autumn of 2014, the first online course for doctoral candidates in Business and Economics was organised. It was an obligatory course that lasted for six weeks and included one elective face-to-face workshop. In order to reduce the workload of the tutor, peer-tutoring was used on the course. Also this course received positive feedback.

Especially for postgraduates online learning can be preferred, as many study at a distance. Since the feedback of the web course for the Economics and Business students was so encouraging, in spring 2015 we decided to arrange the Information Resources and Tools for Research course entirely online for all the doctoral students of the University of Turku for the first time. Transition to the online course was made easier by the fact that already during the previous courses, all course materials were available online via Moodle. 72 doctoral students enrolled to the course, which is in progress while writing this paper. In order to get one credit participants are required to complete seven assignments and there will be one elective face-to- 
face workshop session. Also during this course the participants will work in subject-specific groups.

In future, we will continue to develop the course based on the course feedback. In addition to the qualitative feedback, also pre- and post-questionnaires to measure the student progression would give valuable information. The future of the course looks good. 


\section{References}

Academy of Finland. (2011). Towards quality, transparency and predictability in doctoral training. The Graduate School Working Group's suggestions for doctoral training development. Retrieved from http://www.aka.fi/Tiedostot/Tutkijanura/Towards\%20Quality\%20Transparency\%20and \%20Predictability\%20in\%20Doctral\%20Training.pdf

Association of College and Research Libraries. (2015). Information Literacy Competency Standards for Higher Education. Retrieved from http://www.ala.org/acrl/standards/informationliteracycompetency

Heading, D., Siminson, N., Purcell, C., \& Pears, R. (2010). Finding and Managing Information: Generic information literacy and management skills for postgraduate researchers. International Journal for Researcher Development, 1(3), 206-220. Retrieved from http://www.dspace.cam.ac.uk/handle/1810/224932

Hoffmann, K., Antwi-Nsiah, F., Feng, V., \& Stanley, M. (2008). Library research skills: a needs assessment for graduate student workshops. Issues in Science and Technology Librarianship, (53), 1. doi:10.5062/F48P5XFC

JISC, \& British Library. (2012). Researchers of tomorrow: the research behaviour of generation $Y$ doctoral students. Retrieved from http://www.jisc.ac.uk/publications/reports/2012/researchers-of-tomorrow.aspx

Madden, R. (2014). Information behaviour of humanities PhDs on an information literacy course. Reference Services Review, 42(1), 90-107. doi:10.1108/RSR-07-2013-0034

Merimaa, M. (2012). Tieto tutkijan työpöydälle! : raportti elektronisten aineistojen käytöstä tutkimustyössä. Helsinki: Helsingin yliopisto. Retrieved from http://urn.fi/URN:NBN:fi$\underline{\text { fe201203191575 }}$

Secker, J. (2012). Digital literacy support for researchers: The personalised approach. Retrieved from http://eprints.lse.ac.uk/45810/

Secker, J., \& Macrae-Gibson, R. (2011). Evaluating MI512: an information literacy course for PhD students. Library Review, 60(2), 96-107. doi:10.1108/00242531111113050

Seiler, V. (2009). Challenges in Teaching Information Literacy in Online Courses. In A. Katsirikou, \& C. H. Skiadas (Eds.), Qualitative and quantitative methods in libraries: Theory and applications: Proceedings of the international conference on QQML2009, Chania, Crete, Greece, 26-29 May 2009 (pp. 198-205). Singapore: World Scientific. doi:10.1142/9789814299701_0027

Seiler, V., Miil, K., \& Lepik, K. (2012). How to Fit Teaching of Information Literacy in with Students' Needs: an on-line Credit Course Model from the University of Tartu Library. Liber Quarterly: The Journal of European Research Libraries, 22(1), 42-63. Retrieved from http://persistent-identifier.nl/?identifier=URN:NBN:NL:UI:10-1-112987 